Preventive Care in Nursing and Midwifery Journal

2020; 10(3): 42-51

\title{
Adherence to Treatment Regimen and its Related Factors in Patients Undergoing Coronary Artery Revascularization in the City of Zanjan in 2017
}

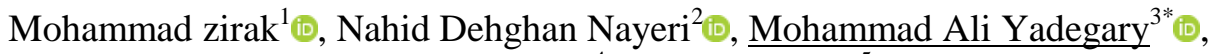 \\ Khatereh Seylani ${ }^{4}$, Elham Navab $^{5}$ (i)

\begin{abstract}
${ }^{1}$ Department of Medical Surgical Nursing, School of Nursing and Midwifery, Zanjan University of Medical Science, Zanjan, Iran ${ }^{2} \mathrm{Ph} . \mathrm{D}$, Prefossor of Nursing of Nursing Management Department, Nursing and Midwifery Care Research Center, Tehran University of Medical Sciences, Tehran, Iran

${ }^{* 3}$ Department of Operating Room and Anesthesiology, school of Nursing and Midwifery, Zanjan University of Medical Sciences, Zanjan, Iran ${ }^{5}$ Ph.D, Associated Professor of Department of Critical Care Nursing, School of Nursing and Midwifery, Tehran University of Medical Sciences,
\end{abstract} \\ ${ }^{4} \mathrm{Ph} . \mathrm{D}$, Assistant Professor in critical care nursing department, faculty of Nursing and Midwifery, Tehran University of Medical Sciences, Tehran, Iran \\ Tehran, Iran
}

*Corresponding Author Address: Zanjan university of medical sciences and health services, Nursing and Midwifery faculty, Mahdavi st, Zanjan, Iran

Tel: 0098-9125422497

Email: Ma.yadegary@gmail.com

Received: 30 Jan $2021 \quad$ Accepted: 9 Feb 2021

\begin{abstract}
Background: Identifying the factors associated with the adherence to treatment regimen is a useful guide for health care providers to provide appropriate treatment regimens and promote the adherence to treatment.

Objectives: The aim of this study was to determine the status of adherence to treatment regimen and its related factors in patients undergoing coronary artery revascularization therapies (CART) in selected hospitals of Zanjan in 2017.

Methods: This correlational study was conducted in Zanjan, Iran in 2017. In total, 318 patients who had undergone CART were selected by systematic random sampling to participate in the study. The study tools included demographic factors, factors related to the disease, and the Nayeri et al questionnaire of adherence to treatment regimen. Descriptive and inferential statistics were used to analyze the data through SPSS software version 23.

Results: Results of this study showed that, the mean score of adherence to treatment regimen by the patients was $128.12 \pm 7.51$ and the status of adherence to treatment regimen was at moderate level. Multiple linear regressions showed that variables such as type of treatment, duration of disease, age, and gender were associated with the adherence to treatment regimen. So that, with the increasing age $(p=0.002)$ and the duration of the disease $(\mathrm{p}=0.034)$, adherence to treatment regimen was also increased. Furthermore, the score of adherence to treatment regimen was better in patients who had coronary artery bypass surgery (CABG) $(\mathrm{p}=0.002)$ than angioplasty procedure, and also it was better in women $(\mathrm{p}=0.032)$ than men.

Conclusion: About half of the patients with CART do not adhere to their treatment regimen. Age, gender, level of education, duration of illness and type of treatment are the predictors of adherence to treatment regimen. Understanding these factors can be used as a guide in designing interventions and conducting further studies to improve the adherence to treatment regimen. Adherence to treatment regimen is not only a complicated variable that has many determinants, but also is a continuous process.
\end{abstract}

Keywords: coronary artery disease, Adherence to treatment regimen, angioplasty, coronary artery bypasses graft surgery

\section{Introduction}

Each year, 17.7 million people die from cardiovascular disease worldwide, accounting for
$31 \%$ of all deaths. The prevalence of coronary artery disease (CAD) is increasing with urbanization, industrialization and lifestyle 
changes. It is estimated that 92.1 million people in the United States will be affected by CAD by 2030. Also, $80 \%$ of deaths due to CAD occur in developing countries [1]. In Iran, cardiovascular disease is the first cause of death and is a major health problem as its dimensions are rapidly increasing [2]. The CART, including the percutaneous intervention (PCI) and coronary artery bypass grafting (CABG). According to increasing number of people with $\mathrm{CAD}$, more patients are undergone angioplasty and $\mathrm{CABG}$ [3]. In Iran, about 35 to 50 thousand cases of heart surgery are performed annually $[4,5]$.

CART does not stop atherosclerosis and gradually other stenosis develop in healthy vessels as well as the repaired ones [6]. In other words, the success of CART depends on the secondary prevention and adherence to the treatment regimen $[3,7]$. This can be achieved with the active participation of patients in treatment and implementation of the treatment team's recommendations, which are referred to as adherence to the treatment regimen.

Adherence to the treatment regimen includes adherence to the dietary recommendation, physical activity, medication, and lifestyle changes. Non-adherence to the treatment regimen is defined as "the extent to which a person's behavior does not coincide with medical or health advice" $[8,9]$.

Adherence to the treatment regimen reduces the risk of CAD and improves the outcomes of CART. Also, helping patients to adapt to lifestyle changes and reduce the risk factors which can play an important role in preventing the recurrence of the disease and its complications. Adherence to the treatment and medication regimens is a major challenge in the chronic patients and their non-adherence to treatment regimen results in undesirable consequences such as recurrence of the disease, exacerbation of symptoms, and increased disability, leading to emergency treatment and urgent hospitalization $[8,10]$.

Despite the importance of adherence to the treatment regimen, numerous study findings have shown that patients do not fully adhere to treatment regimen [11,12]. In advanced countries, $50 \%$ of patients comply with the treatment regimen. In developing countries, non- adherence to treatment regimen is a threat to the treatment and control of chronic patients [13]. In Iran, the rate of adherence to treatment regimen in chronic diseases has been reported in a range of 12.7 to $86.3 \%$, which shows that, the adherence to the treatment status in specific diseases and in different cities needs to be investigated [14-17].

Adherence to the treatment regimen is a major challenge for care and treatment from three aspects. On one hand, non- adherence to the treatment regimen imposes double financial burden on the health system. On the other hand, adherence to the treatment regimen is the key factor in the relationship between the process and treatment outcomes. Also, non- adherence to the treatment regimen disrupts the results of clinical trials [18].

The control of chronic diseases, including cardiovascular disease, depends on the degree of adherence to treatment to a large extent, so that, even the best treatment regimen, if left unadhered, is worthless and impedes the achievement of therapeutic goals. Meanwhile, adequate adherence to treatment regimen improves the quality of life of patients and reduces the cost of treatment [19]. In fact, one of the most important concerns and problems of the health system is the patients non- adherence to the treatment regimen $[20,21]$.

Considering the increasing prevalence of CAD and the importance of treatment adherence in controlling the disease and improving the quality of life of patients undergoing CART, further research on the status of adherence to the treatment regimen and its related factors seems necessary. The aim of this study was to determine the status of adherence to the treatment regimen and its related factors in patients undergoing CART in selected hospitals in Zanjan in 2017.

\section{Methods}

The present study is a correlational study which was conducted from February to July 2017 at hospitals affiliated to the Zanjan University of Medical Sciences. The research population included 1800 patients undergoing CART in hospitals of Zanjan University of Medical Sciences. The sample size was estimated to be 318 people using Cochran's formula. Then, 318 patients who met the inclusion criteria (age range of 18-80 years, reading and writing Level of education and receiving treatment from CART for 
at least 6 months) were selected to participate in the study using systematic random sampling method. After explaining the objectives of the study to the participants, and informed consent was obtained from them.

Data were collected using a two-part questionnaire. The first part included demographic information including age, gender, marital status, educational level and occupational status of the patients. It also contained the information on heart disease, including duration of the disease, type of CART, risk factors, and number of medications used. The second part of the questionnaire was related to the adherence to treatment regimen in patients with coronary artery stenosis, which was designed and validated by Nayeri et al (2018) with 4 dimensions and 35 items. The questionnaire included 35 questions about dietary adherence [13], Healthy lifestyle adherence [7], medication adherence [11], and adherence to exercise and physical activity [4]. All of the above mentioned terms were designed on a 5-point Likert scale as always (5 score), often (4 score), sometimes (3 score), rarely (2 score) and never (1 score). To reduce the chance factor in answering the questions, some of the items were designed in reverse (always one, never 5). This self-reporting tool was completed by the patients. Minimum and maximum potential scores in dietary adherence was 13-65, in adherence to healthy lifestyle was 7-35, in adherence to medication was 11-55, and in adherence to exercise and physical activity was 4-20. The total score of the questionnaire was from 35 to 175 . The higher score in each dimension indicated good adherence to the treatment regimen and a lower score showed poor adherence to the treatment regimen. The cutoff point of the questionnaire was determined as fallow: scores of adherence to treatment less than 105 were considered as low, scores between 106 to 140 were considered moderate and score above 141 were considered as high adherence.

This questionnaire was developed and psychometric in larger study that was done in Tehran University of medical sciences. The reliability of the questionnaire to be 0.862 using the internal consistency (Cronbach's alpha coefficient) and also internal correlation (testretest) to be 0.85 [22].

After collecting the data, they were analyzed by SPSS software version 23 using ANOVA, independent t-test and multiple linear regression with significant level of $(\mathrm{p}<0.05)$.

\section{Results}

This study was performed on 318 patients undergoing CART. At first, the normality of the scores related to the status of adherence to treatment regimen was investigated in general and in four dimensions of diet, healthy lifestyle, medication, and exercise and physical activity using the Kolmogorov-Smirnov test and the normality and symmetry of the data were confirmed. Therefore, parametric tests were used to examine the factors associated with the adherence to treatment regimen.

The mean age of 318 patients was $61.38 \pm 10.66$ years ranging from 33 to 80 years. The majority of patients were male $(67.9 \%)$ and married (98.4\%). About half of the patients $(48.4 \%)$ had reading and writing level of education. The majority of patients $(75.1 \%)$ were employed, and the duration of CAD in most patients $(82.7 \%)$ was two years. The mean and standard deviation of the overall adherence to treatment regimen and its dimensions are presented in Table 1. According to findings $96.9 \%$ of patients had moderate level of adherence to their treatment regimen (Table 1).

Table 1: Adherence to treatment regimen and its dimensions in patients undergoing CART

\begin{tabular}{|c|c|c|c|c|c|c|c|}
\hline \multirow{2}{*}{\multicolumn{2}{|c|}{ dimension adherence to treatment regimen }} & \multicolumn{2}{|c|}{ Low } & \multicolumn{2}{|c|}{ Moderate } & \multicolumn{2}{|c|}{ High } \\
\hline & & Number & Percentage & Number & Percentage & Number & Percentage \\
\hline Dietary & $43.1 \pm 4.02$ & 31 & $9.7 \%$ & 271 & $85.3 \%$ & 16 & $5 \%$ \\
\hline Healthy lifestyle & $32.3 \pm 3.2$ & 2 & $0.6 \%$ & 44 & $13.9 \%$ & 272 & $85.5 \%$ \\
\hline Medication & $37.7 \pm 3.5$ & 7 & $2.2 \%$ & 231 & $72.6 \%$ & 80 & $25.2 \%$ \\
\hline $\begin{array}{c}\text { exercise and } \\
\text { physical activity }\end{array}$ & $14.9 \pm 2.5$ & 107 & $33.6 \%$ & 211 & $66.4 \%$ & 0 & 0 \\
\hline Total & $128.12 \pm 7.51$ & 2 & $0.6 \%$ & 308 & $96.9 \%$ & 8 & $2.5 \%$ \\
\hline
\end{tabular}

The results of this study showed that, there is no correlation between the adherence to treatment regimen and marital status as well as the number of children. 
Results of the study showed that adherence to treatment regimen in the overall score $(\mathrm{P}=0.01)$, healthy lifestyle $(\mathrm{P}=0.01)$, and exercise and physical activity $(\mathrm{P}=0.007)$ was related to age. The LSD post hoc test showed a significant difference in the scores between the age group of less than 49 years and the rest of the age groups $(\mathrm{P}<0.05)$ and the scores of this group were less than the older patients. The scores of other age groups did not differ significantly.

The results indicated that, the status of adherence to treatment regimen (in general and separately in the four dimensions) was better in women than in men (Table 2).

The degree of adherence to the regimen in all dimensions, except for the adherence to medication $(\mathrm{P}=0.9)$, had a significant relationship with the education level. So that, the LSD test showed that, in the dimensions of adherence to diet, adherence to exercise and physical activity and adherence to healthy lifestyle, the scores of patients with secondary education was significantly lower than other patients $(\mathrm{P}<0.05)$. Also, other groups did not differ significantly from each other in terms of education level (Table 2).

In regard to the occupational status, there was no difference between the groups in terms of the dimensions of adherence to medication $(\mathrm{P}=0.2)$ and diet $(\mathrm{P}=0.1)$. However, in the dimensions of adherence to healthy lifestyle $(\mathrm{P}=0.01)$ and exercise and physical activity $(\mathrm{P}=0.03)$, the status of adherence to treatment regimen was significantly correlated to the occupation of the patients. So that, the LSD test showed housewives had a better adherence status than other occupational groups. There was no significant difference between the other occupational groups (Table 2).

Table 2: Mean and standard deviation of scores of adherence to treatment regimen in patients undergoing CART in different dimensions according to the demographic variables

\begin{tabular}{|c|c|c|c|c|c|c|}
\hline \multicolumn{2}{|c|}{$\begin{array}{l}\text { Adherence to treatment regimen } \\
\text { Independent variables }\end{array}$} & \multirow[t]{2}{*}{$\begin{array}{c}\begin{array}{c}\text { Overall } \\
\text { score } \\
\text { Mean } \pm \text { SD }\end{array} \\
124.8 \pm 7.8\end{array}$} & \multirow{2}{*}{$\begin{array}{c}\begin{array}{c}\text { Diet } \\
\text { Mean } \pm \text { SD }\end{array} \\
42.3 \pm 3.9\end{array}$} & \multirow{2}{*}{$\begin{array}{c}\begin{array}{c}\text { Healthy } \\
\text { lifestyle } \\
\text { Mean } \pm \text { SD }\end{array} \\
30.6 \pm 4.2 \\
\end{array}$} & \multirow{2}{*}{$\begin{array}{c}\begin{array}{c}\text { Exercise and } \\
\text { physical } \\
\text { activity } \\
\text { Mean } \pm \text { SD }\end{array} \\
14.2 \pm 3.2 \\
\end{array}$} & \multirow{2}{*}{$\begin{array}{c}\begin{array}{c}\text { Drug } \\
\text { therapy } \\
\text { Mean } \pm \text { SD }\end{array} \\
41.3 \pm 3.8\end{array}$} \\
\hline \multirow{4}{*}{ Age } & Less than 49 years $n=51$ & & & & & \\
\hline & $50-59 \mathrm{n}=98$ & $127.4 \pm 6.7$ & $42.9 \pm 3.5$ & $32.2 \pm 3.03$ & $14.4 \pm 2.6$ & $42.2 \pm 3.6$ \\
\hline & $60-69, n=99$ & $128.4 \pm 7.9$ & $42.7 \pm 4.8$ & $32.6 \pm 3.1$ & $15.2 \pm 2.3$ & $42.1 \pm 4.0$ \\
\hline & Over 70 years $n=70$ & $131.0 \pm 6.5$ & $44.2 \pm 4.2$ & $33.2 \pm 2.4$ & $15.5 \pm 1.9$ & $42.7 \pm 3.4$ \\
\hline$\overline{\mathrm{P}^{*}}$ & & 0.01 & 0.057 & 0.01 & 0.007 & 0.27 \\
\hline \multirow{2}{*}{ Gender } & Male $\quad n=216$ & $126.6 \pm 7.3$ & $42.6 \pm 4.2$ & $31.8 \pm 3.5$ & $14.5 \pm 2.8$ & $41.8 \pm 3.7$ \\
\hline & Female $n=102$ & $131.2 \pm 6.9$ & $44 \pm 3.9$ & $33.3 \pm 2.3$ & $15.6 \pm 1.7$ & $42.9 \pm 3.7$ \\
\hline $\mathrm{P}^{\ldots *}$ & & 0.001 & 0.005 & 0.001 & 0.001 & 0.016 \\
\hline \multirow{2}{*}{$\begin{array}{c}\text { Marital } \\
\text { status }\end{array}$} & Single $\mathrm{n}=5$ & $129 \pm 7.4$ & $42 \pm 4.4$ & $31.4 \pm 4.1$ & $15.6 \pm 1.5$ & $45 \pm 4.6$ \\
\hline & Married $n=313$ & $128 \pm 7.5$ & $43.1 \pm 4.2$ & $32.3 \pm 3.2$ & $14.9 \pm 2.5$ & $42.1 \pm 3.7$ \\
\hline $\mathrm{P}^{* * *}$ & & 0.7 & 0.55 & 0.55 & 0.55 & 0.09 \\
\hline \multirow{4}{*}{$\begin{array}{c}\text { Education } \\
\text { level }\end{array}$} & Reading \& writing $\mathrm{n}=154$ & $129.1 \pm 7.1$ & $43.5 \pm 4.1$ & $32.4 \pm 3.1$ & $15.3 \pm 2.2$ & $42.2 \pm 3.9$ \\
\hline & Primary school $n=116$ & $128.3 \pm 7.2$ & $43.3 \pm 4.1$ & $32.6 \pm 2.7$ & $14.5 \pm 2.6$ & $42.1 \pm 3.7$ \\
\hline & Secondary school $\mathrm{n}=28$ & $127.2 \pm 6.6$ & $42.5 \pm 4.4$ & $32.2 \pm 3.9$ & $14.4 \pm 2.8$ & $42.2 \pm 3.3$ \\
\hline & High school $n=20$ & $120.5 \pm 8.7$ & $39.6 \pm 4.3$ & $29.5 \pm 4.5$ & $13.8 \pm 3.5$ & $41.8 \pm 3.3$ \\
\hline $\mathrm{P}^{*}$ & & 0.001 & 0.001 & 0.001 & 0.007 & 0.9 \\
\hline \multirow{5}{*}{ Occupation } & Housewife $n=101$ & $130.8 \pm 7.2$ & $43.9 \pm 4$ & $33.2 \pm 2.4$ & $15.7 \pm 1.6$ & $42.7 \pm 3.9$ \\
\hline & Laborer $\mathrm{n}=40$ & $127.4 \pm 8.2$ & $42.1 \pm 4.9$ & $31.1 \pm 3.5$ & $14.5 \pm 2.5$ & $42 \pm 3.7$ \\
\hline & Clerk $\mathrm{n}=33$ & $126.7 \pm 7$ & $42.9 \pm 3.5$ & $31.6 \pm 3.5$ & $14.4 \pm 2.5$ & $41.5 \pm 3.6$ \\
\hline & Self-employed $n=90$ & $126.9 \pm 7.2$ & $42.6 \pm 4.1$ & $31.7 \pm 3.8$ & $14.5 \pm 3$ & $42.2 \pm 3.8$ \\
\hline & Retired $\quad \mathrm{n}=54$ & $126.2 \pm 7$ & $42.3 \pm 4.3$ & $32.2 \pm 2.7$ & $14.4 \pm 2.9$ & $41.5 \pm 3.3$ \\
\hline $\mathrm{P}^{n}$ & & 0.01 & 0.1 & 0.01 & 0.03 & 0.2 \\
\hline \multirow{2}{*}{$\begin{array}{l}\text { Number of } \\
\text { children }\end{array}$} & Less than $2 \mathrm{n}=19$ & $127.9 \pm 6.2$ & $42.8 \pm 3.2$ & $32.5 \pm 3.3$ & $14.5 \pm 2.5$ & $42.4 \pm 4.5$ \\
\hline & More than $2 \quad n=299$ & $128.1 \pm 7.5$ & $43.1 \pm 4.2$ & $32.3 \pm 3.2$ & $14.9 \pm 2.5$ & $42.1 \pm 3.7$ \\
\hline $\mathrm{P}^{\prime \prime}$ & & 0.7 & 0.8 & 0.7 & 0.9 & 0.9 \\
\hline
\end{tabular}

This study showed that adherence to treatment regimen in the dimensions of healthy lifestyle $(\mathrm{P}=0.01)$ and exercise and physical activity $(\mathrm{p}=0.05)$ were related to the type of treatment, so that patients undergoing $\mathrm{CABG}$ had better adherence to treatment than other treatment groups (Table 3).

Adherence to treatment regimen was related to the duration of the disease in the dimension of adherence to medication, so that patients with a 
long history of disease had a better treatment adherence $(\mathrm{P}=0.04)$, (Table 3$)$.

Adherence to treatment regimen in the dimensions of dietary adherence $(\mathrm{P}=0.02)$ and adherence to healthy lifestyle $(\mathrm{P}=0.01)$ were significantly correlated to the risk factors of patients. LSD test showed that patients with more risk factors had a better adherence in the dimensions of dietary adherence and adherence to healthy lifestyle, than patients with a single risk factor $(\mathrm{P}<0.05)$, (Table $3)$.

Regarding the number of medications, the degree of adherence to the treatment regimen was not correlated to the number of drug used in any of the dimensions, but in the overall scores, the

Table 3: The mean and standard deviation of the scores of adherence to treatment regimen in the patient undergoing CART in different dimensions according to the variables of the disease condition

\begin{tabular}{|c|c|c|c|c|c|c|}
\hline $\begin{array}{r}\text { Adhe } \\
\text { Independent }\end{array}$ & ce to treatment regimen & $\begin{array}{c}\text { Overall } \\
\text { score } \\
\text { Mean } \pm \text { SD }\end{array}$ & $\begin{array}{c}\text { Diet } \\
\text { Mean } \pm S D\end{array}$ & $\begin{array}{c}\text { Healthy } \\
\text { lifestyle } \\
\text { Mean } \pm \text { SD }\end{array}$ & $\begin{array}{c}\text { Exercise and } \\
\text { physical } \\
\text { activity } \\
\text { Mean } \pm \text { SD }\end{array}$ & $\begin{array}{l}\text { Drug therapy } \\
\text { Mean } \pm \text { SD }\end{array}$ \\
\hline \multirow{2}{*}{$\begin{array}{l}\text { Duration of } \\
\text { disease }\end{array}$} & $\begin{array}{l}2 \text { or less than } 2 \text { years } \\
n=279\end{array}$ & $127.9 \pm 7.4$ & $42.9 \pm 4.3$ & $32.3 \pm 3.2$ & $14.8 \pm 2.6$ & $42.2 \pm 3.7$ \\
\hline & More than 2 years & $129.3 \pm 7.6$ & $44.3 \pm 3.3$ & $32.4 \pm 3.2$ & $15.2 \pm 2.1$ & $41.7 \pm 4.1$ \\
\hline $\mathrm{P}^{*-1}$ & & 0.2 & 0.04 & 0.8 & 0.4 & 0.4 \\
\hline \multirow{4}{*}{ Risk factor } & High cholesterol $n=80$ & $128.6 \pm 8.1$ & $43.6 \pm 4.4$ & $32.5 \pm 2.9$ & $14.6 \pm 2.7$ & $42.4 \pm 4.2$ \\
\hline & Hypertension $n=63$ & $130.4 \pm 6.3$ & $44.2 \pm 3.9$ & $33 \pm 2.1$ & $14.9 \pm 1.9$ & $42.8 \pm 3$ \\
\hline & Diabetes $\quad n=42$ & $130.4 \pm 7.2$ & $44.4 \pm 3.5$ & $32.5 \pm 3.2$ & $15 \pm 2.5$ & $43 \pm 3.8$ \\
\hline & $\begin{array}{c}\text { Others (more than } 1 \text { risk } \\
\text { factor) } \quad n=84\end{array}$ & $127.6 \pm 6.8$ & $45.5 \pm 4.1$ & $34.4 \pm 3.2$ & $15 \pm 2.5$ & $41.9 \pm 3.5$ \\
\hline $\mathrm{P}^{*}$ & & 0.01 & 0.02 & 0.01 & 0.7 & 0.1 \\
\hline \multirow{2}{*}{$\begin{array}{l}\text { Number of } \\
\text { medication }\end{array}$} & 5 medications $n=98$ & $127.4 \pm 7.7$ & $42.8 \pm 4.4$ & $31.8 \pm 3.5$ & $14.8 \pm 2.9$ & $41.8 \pm 3.2$ \\
\hline & 7 medications $n=65$ & $129.1 \pm 6$ & $42.4 \pm 3.6$ & $32.5 \pm 3.3$ & $15.2 \pm 2.4$ & $42.3 \pm 3.4$ \\
\hline $\mathrm{P}^{*}$ & & 0.02 & 0.17 & 0.2 & 0.055 & 0.5 \\
\hline \multirow{3}{*}{$\begin{array}{l}\text { Coronary } \\
\text { artery }\end{array}$} & 1 vessel $n=92$ & $127.4 \pm 9$ & $43.2 \pm 4.7$ & $31.5 \pm 4.1$ & $14.7 \pm 2.8$ & $42.2 \pm 4$ \\
\hline & 2 vessels $\quad n=97$ & $128.4 \pm 6.8$ & $43 \pm 4$ & $32.6 \pm 2.7$ & $14.9 \pm 2.4$ & $42.1 \pm 3.6$ \\
\hline & 3 vessels $\quad n=123$ & $128.1 \pm 7.5$ & $43.1 \pm 4.2$ & $32.3 \pm 3.2$ & $14.9 \pm 2.5$ & $42.2 \pm 3.7$ \\
\hline $\mathrm{P}^{*}$ & & 0.2 & 0.18 & 0.003 & 0.3 & 0.4 \\
\hline \multirow{2}{*}{$\begin{array}{c}\text { Type of } \\
\text { treatment }\end{array}$} & CABG $\quad n=164$ & $127.5 \pm 8.3$ & $43 \pm 4.5$ & $31.9 \pm 3.6$ & $14.6 \pm 2.8$ & $42.3 \pm 3.7$ \\
\hline & PCI ، $\mathrm{n}=154$ & $128.7 \pm 6.5$ & $43.2 \pm 3.8$ & $32.8 \pm 2.8$ & $15.1 \pm 2.3$ & $42 \pm 3.7$ \\
\hline $\mathrm{P}^{\mathrm{F} * \mathrm{~T}}$ & & 0.1 & 0.7 & 0.01 & 0.05 & 0.4 \\
\hline
\end{tabular}

*The significance level related to the ANOVA test,

** the significance level related to independent-test

In the study of multiple analysis of the factors related to the overall rates of adherence to treatment regimen and other variables, the results of the study showed that, the variables of the type of treatment, the duration of the disease, age, and gender were correlated to adherence to treatment regimen. So that, with the increasing age $(\mathrm{p}=0.002)$ and the duration of the disease patients who were taking 7 drugs, had higher scores compared to other patients $(\mathrm{P}=0.02)$, (Table 3).

This study showed that adherence to treatment regimen was only correlated to the number of involved coronary arteries $(\mathrm{P}=0.003)$ only in the dimension of adherence to healthy lifestyle. The LSD test showed that, the degree of adherence in the group whose all three coronary arteries were involved was significantly higher than other groups $(\mathrm{P}<0.05)$, and there was no significant difference between the other groups (Table 3 ). 
Table 4: Coefficients of Multiple Linear Regression Model in Investigating the Relationship between Adherence to Treatment Regimen and Independent Variables

\begin{tabular}{ccccc}
\hline Independent variables $^{*}$ & $\mathrm{~B}$ & Std. Error & $\mathrm{t}$ & Sig. \\
\hline Type of treatment & 0.252 & 0.096 & 4.253 & 0.002 \\
\hline Age & 0.132 & 0.043 & 3.070 & 0.002 \\
\hline Gender $^{* *}$ & 2.808 & 1.305 & 2.152 & 0.032 \\
\hline
\end{tabular}

\section{*Reference group=PCI \\ ${ }^{* *}$ Reference group $=$ male}

\section{Discussion}

The results of this study showed that, the status of adherence to the treatment regimen was at moderate level in most of the participants. Compared to similar studies in Iran [23,24], the degree of adherence to the treatment regimen and its dimensions in patients undergoing CART was improved in this study. One of the factors that should be considered is the implementation of health plan with three goals of reducing people's cost, promoting fairness in access to health services and developing health infrastructure. These goals are fundamentally important in improving adherence to the treatment regimen.

In this study, the age was one of the factors associated with adherence to treatment regimen, so that younger patients (under 49 years of age) had a general adherence to healthy lifestyle, and less adherence to exercise and physical activity. In many studies, controversial findings have been obtained regarding the relationship between age and adherence to treatment regimen. So that, in some studies, younger people and in some other studies the older people, had lower adherence to treatment regimen [25-27]. In the elderly population over 75 years of age, there are problems with adherence to the treatment regimen due to the cognitive problems. The highest rate of Adherence to treatment regimen has been reported in 60 to 70 years old adults [28]. Young patients have lower adherence to treatment regimen due to the lack of knowledge about the consequences of non- Adherence to treatment regimen and their role in treatment and control of the disease. They are also involved in work and occupational activity that consider it as an appropriate alternative to physical activity and regular exercise. This could explain the lower adherence to treatment regimen in terms of exercise and physical activity among these patients.
Gender was one of the factors associated with the Adherence to treatment regimen in this study. Women, although they did not differ in overall Adherence to treatment regimen, had better adherence to treatment regimen than men in terms of its dimensions. Studies have reported contradictory findings on the relationship between gender and Adherence to treatment regimen [27, 29]. One of the factors associated with adherence to treatment regimen is the belief of individuals regarding the illness, the seriousness of disease consequences, and the effectiveness of recommended measures to reduce the risk or control it, which extends in the form of health belief model. Women have a higher perceived sensibility and perceived threat than men and are more likely to seek help for their problems. This could affect their adherence to the treatment regimen [30].

Unexpectedly, patients with a higher education level had lower adherence to treatment regimen in the dimension of dietary adherence, adherence to exercise and physical activity, and adherence to healthy lifestyle. It seems that, although health literacy improves the adherence to treatment regimen and therapeutic outcomes [31,32], higher education level does not necessarily mean higher levels of health literacy.

Also, in regard to the occupational status, housewives had a better adherence to healthy lifestyle and exercise and physical activity. This could be due to the fact that; housewives have more time to spend on such activities. On the other hand, in this study, gender was one of the factors contributing to the improvement of adherence to treatment regimen and female patients had better adherence to treatment regimen. However, the majority of women were housewives. 
There was no statistically significant difference between the demographic factors and the dimension of medication adherence, which could be due to patients' perception of adherence with the treatment regimen. Most patients perceived adherence to treatment regimen as the regular use of prescriptive drugs, and believed that, the destructive effects of non- adherence to medication therapy are much faster and more severe than other dimensions.

Patients undergoing CABG surgery had a better adherence to treatment regimen in the dimension of adherence to healthy lifestyle and adherence to exercise and physical activity than patients with angioplasty. Psychological factors are among the factors that influence patient's adherence to treatment regimen. One of these factors is the attitude towards the disease and treatment, and how the patient is exposed to the risk of heart disease [33]. Patients undergoing $\mathrm{CABG}$ face more serious risks, which can contribute to their adherence to treatment regimen by increasing their perceived sensitivity and threats. Additionally, patients undergoing PCI experience fewer and milder symptoms of ischemia, so they feel less in need of adherence to the treatment regimen [25].

In this study, patients with a long history of disease had a better adherence to treatment regimen. Although no relationship was found between other dimensions of general adherence and the duration of the disease, the knowledge and awareness of patients about the duration of treatment was one of the important factors in improving their adherence to the treatment regimen [34]. With a prolonged duration of treatment, patients' understanding and knowledge of the chronic conditions of the disease will improve, and this can increase their adherence to treatment regimen.

Patients with more risk factors had better adherence to treatment regimen in the dimensions of dietary adherence and adherence to healthy lifestyle. Patients with a higher number of involved coronary arteries, three vessel disease (3VD), had better adherence to treatment regimen than patients who had stenosis in single vessel disease (SVD) and two vessels disease (2 VD). It seems that patients with higher number of risk factors and more severe illness (more involved vessels) have a higher perceived sensitivity and perceived risk, which according to the health belief model, leads to better adherence to treatment regimen.

In line with the results of this study, studies have shown that the presence of another illness or risk factor at the onset of the disease improves the adherence to treatment regimen [35-37]. This issue can also be due to the higher perceived sensitivity and perceived threat of patients with more risk factors (The greater perceived threat, greater the adherence to treatment regimen).

Although the use of more drugs in the elderly population due to cognitive problems is one of the predictors of non- adherence to treatment regimen $[38,39]$, in this study, the overall adherence of patient was associated with the use of more drugs. This contradiction can be due to the higher severity of the disease or the higher number of risk factors in the patients who were taking more drugs.

\section{Conclusion}

In this study, we have identified the factors associated with the adherence to treatment regimen in patients undergoing CART, but according to the World Health Organization (WHO), patients are not solely responsible for their non- adherence to treatment regimen. Therefore, more research should be conducted with appropriate interventions on other factors that affect the adherence to treatment regimen, including health care systems and service providers.

Adherence to treatment regimen is not only a complicated variable that has many determinants, but also is a continuous process. Therefore, promotion of adherence to treatment regimen should be considered as one of the most important programs of health system, and interventions should be implemented to improve it.

Limitations: Since adherence to treatment regime is affected by measurement method, it is recommended to design and implement studies using other measurement methods.

\section{List of abbreviation:}

(CAD): coronary artery disease

(CABG): coronary artery bypass surgery

(PCI): Percutaneous coronary intervention

(3VD): Three vessel disease

(SVD): single vessel disease

(2 VD): Two vessels disease. 
(WHO): World Health Organization

\section{Acknowledgments:}

All procedures performed in studies involving human participants were in accordance with the Ethics Committee of the Tehran Faculty of Nursing and Midwifery with No: IR.TUMS.FNM.REC.1396.2689 and with the 1964 Helsinki declaration and its later amendments or comparable ethical standards. Informed consent was obtained from all individual participants included in the study. the study setting and started sampling only after obtaining necessary approvals and permissions from the Ethics Committee of Tehran University of Medical Sciences, Tehran, Iran, and the Research Administration of Zanjan University of Medical Sciences, Zanjan, Iran. Participants were provided with obvious explanations about the aim of the study, confidential management of the study data, and perfect right of voluntary withdrawal from the study and then, their consents for participation were secured.

This study is a part of $\mathrm{PhD}$ dissertation in Nursing approved by Tehran University of Medical Sciences, Tehran, Iran. We are thankful to the administrators of the University and the participants of the study.

\section{Conflict of interest}

The authors declare that they have no competing interests.

\section{Funding:}

No funding or sponsorship was received for this study or publication of this article. Article processing charges were funded by the authors

\section{References}

1. Members WG, Benjamin EJ, Blaha MJ, et al. Heart disease and stroke statistics-2017 update: a report from the American Heart Association. Circulation. 2017; 135(10): e146-e 603.

2. Gholizadeh B, Ebrahimi S, Zakerimoghadam a, Shahsavari H, Naboureh A. Effects of selfmanagement program and telephone follow up on medical adherence in patients with ischemic heart disease. koomesh. 2017; 19(1): 213-19. [In Persian]

3. Thomas M, Hariharan $M$, Rana S. Psychological distress as predictor of adherence and prognosis among patients undergoing coronary artery bypass grafting. J Indian Acad Appl Psychol. 2016; 42(1): 161-71.

4. allahbakhshian a, hasankhani h, mohammadi $\mathrm{E}$, zamanzadeh v, ghafari s. Second life after angioplasty: a qualitative study. J Cardiovasc Nurs. 2014; 4(2): 52-63. [In Persian]

5. Pourghane P, Hosseini M-A, Mohammadi F, Ahmadi F, Tabari R. Patient's Perception of Cardiac Rehabilitation after Coronary Artery Bypass Graft (CABG): A Qualitative Study. J Mazandaran Univ Med Sci. 2013; 23(106): 61-76. 6. Andreoli TE, Fitz JG, Benjamin I, Griggs RC, Wing EJ. Andreoli and Carpenter's Cecil Essentials of Medicine. $8^{\text {th }}$ ed. Philadelphia: Saunders; 2010.

7. Sanaie N, Nejati S, Zolfaghari M, Alhani F, Kazemnezhad A. The effects of family-based empowerment on family cooperation in following patient treatment regime after coroner arteries bypass surgery. Mod Care J. 2014; 11(1): 19-27. [In Persian]

8. Masror Roudsari D, Dabiri Golchin M, Haghani H. Relationship between adherence to therapeutic regimen and health related quality of life in hypertensive patients. Iran J Nurs. 2013; 26(85): 44-54. [In Persian]

9. Rafii F, Fatemi NS, Danielson E, Johansson $\mathrm{CM}$, Modanloo M. Compliance to treatment in patients with chronic illness: A concept exploration. Iran J Nurs Midwifery Res. 2014; 19(2): 159-67.

10. Gentz CA. Perceived learning needs of the patient undergoing coronary angioplasty: an integrative review of the literature. Heart Lung. 2000; 29(3): 161-72.

11. Nahapetyan A. Relationship between Patients' Knowledge about Post Operative Risk Factors after Coronary Artery Bypass Surgery (CABG) and Adherence to Medication and Lifestyle Changes in Armenia [dissertation]. Armenia, Yerevan: College of Health Sciences, American University of Armenia. 2007.

12. Michels K, Willett W, Graubard B, et al. A longitudinal study of infant feeding and obesity throughout life course. Int $\mathbf{J}$ obes. 2007; 31(7): 1078- 85.

13. Axelsson M, Brink E, Lundgren J, Lötvall J. The influence of personality traits on reported adherence to medication in individuals with 
chronic disease: an epidemiological study in West Sweden. PloS one. 2011; 6(3): e18241.

14. Abbasi M, Salemi S, Fatemi NS, Hosseini F. Hypertensive Patients, Their Compliance Level And Its'relation To Their Health Beliefs. Iran J Nurs. 2005; 18(41): 61-8.

15. Hadi N, Rostami Gn, Jafari P. A study on the determining factors for compliance to prescribed medication by patients with high blood pressure. Jundishapur Sci Med J. 2006; 4(3): 223-29. [In Persian]

16. Hashem Dabaghian F, Karbaksh M, Sedaghat M, Soheyli Khah S. Drug compliance in patients with type 2 diabetes mellitus in Shariati and Imam Khomeini hospitals. Payesh. 2005; 4(2): 103-11. [In Persian]

17. Parsa-Yekta Z, Zakeri Moghaddam M, Mehran A, Palizdar M. Study of medication compliance of patients with coronary heart diseases and associated factors. Hayat. 2004; 9(4): 34-43. [In Persian]

18. Vermeire E, Hearnshaw H, Van Royen P, Denekens J. Patient adherence to treatment: three decades of research. A comprehensive review. J Clin Pharm Ther. 2001; 26(5): 331-42.

19. Banning $M$. Enhancing older people's concordance with taking their medication. $\mathrm{Br} \mathrm{J}$ Nurs. 2004; 13(11): 669-74.

20. Jin J, Sklar GE, Oh VMS, Li SC. Factors affecting therapeutic compliance: A review from the patient's perspective. Ther Clin Risk Manag. 2008; 4(1): 269- 86.

21. Nemes MIB, Helena ETdS, Caraciolo JM, Basso CR. Assessing patient adherence to chronic diseases treatment: differentiating between epidemiological and clinical approaches. Cad Saúde Pública. 2009; 25: S392-S400.

22. Nayeri ND, Yadegary MA, Seylani K, Navab E. Development and Psychometric Evaluation of Coronary Artery Disease Treatment Adherence Scale. Cardiol Ther. 2019; 8(1): 103-15.

23. Poshtchaman Z, Jadid Mm, Atashzadeh Sf, Akbarzadeh $\mathrm{Ba}$. Assessing patient adherence to treatment after coronary artery bypass graft. J Sabzevar Univ Med Sci. 2015; 22(4): 668-75. [In Persian]

24. Paryad E, Kazemnezhad Leili E, Booraki S, SadeghiMeibodi A, Nassiri Sheikhani N. Study status of care adherence and its related factors in patients undergoing. J Holist Nurs Midwifery. 2015; 25(3): 34-45.
25. Rodriguez F, Cannon CP, Steg PG, et al. Predictors of long-term adherence to evidence-based cardiovascular disease medications in outpatients with stable atherothrombotic disease: findings from the REACH Registry. Clin Cardiol. 2013; 36(12): 721-27.

26. Kulik A, Ruel M, Jneid H, et al. Secondary prevention after coronary artery bypass graft surgery: a scientific statement from the American Heart Association. Circulation. 2015; 131(10): 927-64.

27. Lee HY, Cooke CE, Robertson TA. Use of secondary prevention drug therapy in patients with acute coronary syndrome after hospital discharge. J Manag Care Pharm. 2008; 14(3): 271-80.

28. Dunbar-Jacob J, Mortimer-Stephens M. Treatment adherence in chronic disease. $\mathrm{J}$ clin epidemiol. 2001; 54(12): S57-S60.

29. Granger BB, Ekman I, Granger CB, et al. Adherence to medication according to sex and age in the CHARM programme. Eur J Heart Fail. 2009; 11(11): 1092-98.

30. Davari S, Dolatian M, Maracy MR, Sharifirad G, Safavi SM. The Effect of A Health Belief Model ( HBM)- based Educational Program on the Nutritional Behavior of Menopausal Women in Isfahan. Iran J Med Educ. 2011; 10(5): 126372. [In Persian]

31. Noureldin M, Plake KS, Morrow DG, Tu W, $\mathrm{Wu}$ J, Murray MD. Effect of health literacy on drug adherence in patients with heart failure. Pharmacotherapy. 2012; 32(9): 819-26.

32. Magnani JW, Mujahid MS, Aronow HD, et al. Health Literacy and Cardiovascular Disease: Fundamental Relevance to Primary and Secondary Prevention: A Scientific Statement From the American Heart Association. Circulation. 2018; 138(2): e48-e74.

33. Iakovleva MV. Adherence to treatment after coronary bypass surgery: Psychological aspects. Revista Iberoamericana de Psicología y Salud. 2016; 7(1): 9-14.

34. Ke X-j, Yu Y-f, Guo Z-1, et al. The utilization status of aspirin for the secondary prevention of ischemic stroke. Chin Med J. 2009; 122(2): 16568.

35. Bushnell CD, Zimmer LO, Pan W, et al. Persistence with stroke prevention medications 3 
months after hospitalization. Arch Neurol. 2010; 67(12): 1456-63.

36. Ji R, Liu G, Shen $H$, et al. Persistence of secondary prevention medications after acute ischemic stroke or transient ischemic attack in Chinese population: data from China National Stroke Registry. Neurol Res. 2013; 35(1): 29-36. 37. Østergaard K, Madsen C, Liu M-L, Bak S, Hallas J, Gaist D. Long-term use of antiplatelet drugs by patients with transient ischaemic attack. Eur J Clin Pharmacol. 2014; 70(2): 241-48.
38. Sabaté E. Adherence to long-term therapies: evidence for action: World Health Organization; 2003.

39. Al AlShaikh S, Quinn T, Dunn W, Walters M, Dawson J. Predictive factors of non-adherence to secondary preventative medication after stroke or transient ischaemic attack: A systematic review and meta-analyses. Eur Stroke J. 2016; 1(2): $65-$ 75 . 